\title{
Methodology for instantaneous average exhaust gas mass flow rate measurement
}

\author{
Natalia Fonseca González a,*, Jesús Casanova Kindelán ${ }^{\text {b }}$, José María López Martínez ${ }^{\mathrm{c}}$ \\ ${ }^{a}$ Universidad Politécnica de Madrid, Mining and Energy Engineering School, Department of Energy and Fuels, c/Rios Rosas 21, 28003 Madrid, Spain \\ ${ }^{\mathrm{b}}$ Universidad Politếcnica de Madrid, Industrial Engineering School, Department of Energy Engineering, c/José Gutiérrez Abascal 2, 28006 Madrid, Spain \\ ${ }^{c}$ Universidad Politécnica de Madrid, University Institute for Automobile Research, INSIA - Campus Sur UPM, 28031 Madrid, Spain
}

\begin{abstract}
A B S T R A C T
This paper presents a new methodology for measurement of the instantaneous average exhaust mass flow rate in reciprocating internal combustion engines to be used to determinate real driving emissions on light duty vehicles, as part of a Portable Emission Measurement System (PEMS). Firstly a flow meter, named MIVECO flow meter, was designed based on a Pitot tube adapted to exhaust gases which are characterized by moisture and particle content, rapid changes in flow rate and chemical composition, pulsating and reverse flow at very low engine speed. Then, an off-line methodology was developed to calculate the instantaneous average flow, considering the "square root error" phenomenon. The paper includes the theoretical fundamentals, the developed flow meter specifications, the calibration tests, the description of the proposed off-line methodology and the results of the validation test carried out in a chassis dynamometer, where the validity of the mass flow meter and the methodology developed are demonstrated.
\end{abstract}

\section{Introduction}

Accurate measurement of the instantaneous average exhaust gas mass flow rate is necessary when motor vehicle mass emissions and fuel consumption factor are to be measured in real life [32]. The exhaust mass flow rate as well as the concentration of the gaseous pollutants $\left(\mathrm{CO}, \mathrm{HC}, \mathrm{NO}_{x}\right.$, etc.) emitted by an internal combustion engine are continuously changing as the torque and rotational speed of the engine changes due to the variability of the vehicle speed, road slope, acceleration, etc. [10,32].

The exhaust gas mass flow rate from reciprocating internal combustion engines has some characteristics that avoid the use of a conventional gas flow meters for its direct measurement, such as high concentration of condensable water vapour, particulate matter content, changes in the chemical composition and pulsating flow including reverse flow at very low engine speeds [13], $[26,34,35,41]$.

For those reasons, most pollutant emissions measurement procedures used in standardized type approval tests are based in constant volume flow rate, either by using constant engine operating conditions or constant flow sampling techniques, such as the

\footnotetext{
* Corresponding author.

E-mail addresses: natalia.fonseca@upm.es (N. Fonseca González), jesus.casanova@upm.es (J. Casanova Kindelán), josemaria.lopez@upm.es (J.M. López Martínez).
}

CVS (Constant Volume Sampling) testing procedures prescribed in worldwide accepted emission regulations. Also, in these testing procedures, the exhaust gases are diluted with fresh air to avoid water condensation, soot particles deposition and to damper flow pulsation $[23,36,41,43]$. Such CVS systems along with chassis dynamometer in the case of light duty vehicles and engine test bench in the case of heavy duty engines, can only measure the total amount of emissions in terms of mass emitted throughout the test [38]. The advantages are its easy implementation and that the repeatability is good enough, but they cannot give information about the time resolved influence of the different factors and they cannot conduct a modal analysis of pollutant formation in the real transient conditions of the engine. In some of these techniques, exhaust gas flow could be measured in real time in stationary engine test benches or chassis dynamometers, but it is not possible to use in on-board applications due to its size and heavy weight $[36,41]$.

In the last 15 years different flow meters have been developed for direct exhaust gas flow measurement, such as ultrasonic, turbine, vortex type, and differential pressure flow meters $[8,20-$ 22,29,34-37,42]. Ultrasonic flow meters, are among the most effective to flow measure even if pulsating or backflow is present [29], but have some disadvantages because they are affected by the temperature, density and viscosity of the fluid [35,37]. Different techniques have been developed to overcome these problems like the work developed at the University of Leoben [16][17,18] 
and the flow meter developed by AVL $[3,19]$.

Other flow metering devices such as turbine and vortex type flow meters have problems when dealing with pulsating flow [20], [21] because of the inertial effects and when used with high temperature gases [35]. Other flow meters such as those based on hot wire or hot plate anemometry are seriously affected by the deposition of particulate matter when exhaust gases are to be measured $[20,35,39]$.

On the other hand, differential pressure flow meters, such as orifice plates, nozzles, venturi tubes, laminar flow elements or Pitot tubes, are currently the most widely used for on-board exhaust gas measurement because of its simplicity [25][28,29]. Differential pressure flow meters are based on the measurement of the pressure drop across a pipe restriction which is related to the flow speed by Bernoulli's equation, being this relation not a linear function [20] causing what is known as the mechanism of the "square root error" [29]. Therefore, the average volume flow rate is not represented by average differential pressure, so the average results obtained with these types of gas flow meters are seriously affected by the pulsation of the flow that causes huge errors [36]. The first differential pressure flow meter used successfully to measure exhaust gas flow in on-board testing conditions was the Annubar flow meter, recommended by the EPA, which is a multiport averaging Pitot type tube sensor [5,35]. Other differential pressure gas flow meters with different configurations have been developed for measuring the flow of recirculated exhaust gases in engines equipped with EGR such as the ones developed by Henderson et al. [12] and Colvin et al. [6].

Currently instrumentation technology and methods to measure exhaust gas mass flow, emission factors and consumption factors in real use (on-board) are considered mature [33]. Most of the commercially available Portable Emission Measurement Systems (PEMS) use Pitot type flow meters to measure instantaneous average exhaust gas flow in conjunction with electronic signal post-processing, because they are able to measure high-temperature fluids and are more effective in size and cost than other devices $[4,25,28,31]$. However, the precise measurement of the average mass flow rate of exhaust gases from an engine with a Pitot tube is a complex process in which it is necessary:

- to prevent clogging by moisture or particles through a suitable design of the sensing tube,

- to have a differential pressure sensor with high performance which is able to measure negative values,

- to synchronously measure the exhaust gases temperature and absolute pressure,

- to design a methodology,

- to have a powerful data logger and computation systems that allows the calculation of the average mass flow rate in real time, such as the Pitot type exhaust mass flow meter patented by Nakamura et al. [28].

In a Pitot type exhaust gas flow meter, the most expensive instrument is the differential pressure sensor because it needs high sensitivity, low reaction time, low hysteresis, low influence effects, low thermal errors, automatic zero adjustment and long term stability. It is due to the fact that in a Pitot-type flow meter the volume flow rate depends on the square root of the differential pressure; so small zero setting errors in the differential pressure measure, overcome in significant errors in the calculated volume flow rate. In addition, the measurement accuracy at very low flow rate strongly influences the calculation of the emissions and the fuel consumption factors in real urban traffic, where significant periods of time with the engine at idle are frequent [10].

Given the above, a Pitot-type flow meter and off-line methodology for measuring instantaneous average exhaust gas mass flow developed by the authors, are presented in this paper. The main advantage of the developed mass flow meter is that it uses standard specifications instruments and conventional data acquisition, processing and storage systems. The paper includes the theoretical fundamentals of the mass flow rate calculations and the specifications of the developed flow meter. The calibration procedures and tests results are also presented and discussed. The computation methodology for the instantaneous average flow measurement, designed especially when pulsating flow appears at very low engine speeds, is based on the fact that differential pressure waves can be approximated to a sine wave with a frequency equal to twice the engine speed for a four-stroke 4-cylinder engine.

\section{Theoretical approach}

\subsection{Pulsating exhaust flow}

Pulsating flow is a specific type of unsteady flow, where a more or less regular cyclic variation in flow velocity is superimposed on a constant time-averaged volume flow rate [27]. In an internal combustion engine, pulsating flow is due to the cyclic discharge of combustion gases through the exhaust valve that have a sequential lift movement. Two pressure waves are generated by the exhaust flow process: the first one, much more intense, is caused by the sudden opening of the exhaust valves during the blowdown period that creates a choked flow, the second one, less intense, occurs when the pistons move upward through the exhaust stroke. In addition, a small quantity of backflow of exhaust gas into the cylinder might occur during overlap periods and is largest at the lowest engine speeds and in Otto engines at part load.

The exhaust stroke pours a certain amount of gas in the exhaust pipe creating a flow wave that travels along the exhaust pipe to the open end, which is dampened by the fluid friction. The beginning of the exhaust valve opening creates also a shock wave that travels at a higher velocity to the exhaust tail pipe end. The pressure rise of the exhaust shock wave and the flow pulse depends on cylinder pressure at the end of the expansion stroke of the engine, which is a function of the engine type (Otto or diesel), the engine speed, the engine load and other engine designs and calibration parameters. The pressure waves propagate at a velocity slightly higher than the local speed of sound, through the entire exhaust system: exhaust manifold and pipes, catalytic converter and a muffler or silencer. Due to wave propagation phenomena, geometrical configuration of the exhaust system and frictional losses, pressure waves suffer reflection, refraction and attenuation and also interact with other waves in multi-cylinder engines [2] and reach the exhaust tail pipe end significantly dampened. The primary frequency of such pressure waves match up to the frequency of the exhaust processes of individual cylinders [14].

This means that the exhaust gas flow has a stationary component that varies with operating conditions changes of the engine and an oscillating higher frequency component that corresponds to the pressure wave described above. Then, for the instantaneous emission factors calculation of engines in real use, it is necessary to know the instantaneous averaged exhaust gas volume flow rate, obviating the oscillatory component that does not provide useful information. It has a higher frequency than load and speed changes of the engine. Therefore, although the volume flow rate of exhaust gas is a pulsating flow, for studies of emissions and consumption of an internal combustion engine, the average volume flow rate is of interest and has the advantage that it can be considered as a quasi - steady variable.

The average component of the exhaust flow (mass flow rate $\dot{m}_{E}$ ) for a four-stroke engine can be calculated as shown in Eq. (1). The 
mass flow rate of an engine depends on the air density at the intake manifold $\left(\rho_{A}, o\right)$, the volumetric efficiency $\left(\eta_{V}\right)$, the engine displacement $\left(V_{d}\right)$, the engine speed $(n)$ and the air/fuel ratio $\left(m_{F}\right.$ $\left(m_{A}\right)$.

$\dot{m}_{E}=\frac{1}{2} \cdot \eta_{V} \cdot V_{d} \cdot n \cdot \mathrm{Q} A, 0 \cdot\left[1+\left(m_{F} / m_{A}\right)\right]$

In order to obtain a mathematical model for the behavior of the pressure and flow waves described above, it is initially considered one-dimensional compressible fluid in undisturbed state, having the uniform properties: pressure $P_{0}$ and velocity $v_{0}$. Then, it is assumed that a weak pressure disturbance, such as an acoustic wave [44] is propagated in the fluid, with a propagation speed that is fast enough to warrant assuming adiabatic wave propagation. The fluid is assumed to be inviscid, therefore, its motion may be assumed to be isentropic because of the small pressure disturbance. Under these considerations, the properties of the onedimensional compressible fluid subjected to a small disturbance are:

$P=P_{0}+p^{\prime} \quad v=v_{0}+v^{\prime}$

where the perturbation quantities for pressure and velocity are $p^{\prime}$ and $v^{\prime}$ respectively. Therefore, the governing equations for the isentropic process under consideration are Continuity equation Eq. (3) and Momentum (Euler) equation Eq. (4).

$\frac{\partial \mathrm{Q}}{\partial t}+\nabla \cdot(\mathrm{Q} v)=0$

$\frac{\partial v}{\partial t}+v \cdot \nabla v+\frac{1}{\mathrm{e}} \nabla P=0$

These equations can be solved using the finite difference method [14] or other numerical techniques [26]. These equations, however, can be simplified assuming a linear behavior of the gas flow rate and ignoring all second order and smaller terms. Thus, the classical one-dimensional wave equation [44] is obtained: Eq. (5) for pressure perturbation ( $p^{\prime}$ ) and Eq. (6) for particle velocity $(v)$, both equations depending on the speed of sound (c) [36].

$\nabla^{2} p^{\prime}-\frac{1}{c^{2}} \frac{\partial^{2} p^{\prime}}{\partial t^{2}}=0$

$\nabla^{2} v-\frac{1}{c^{2}} \frac{\partial^{2} v}{\partial t^{2}}=0$

Since the oscillating component of the exhaust flow is due to the sequential opening of exhaust valves, the solution of this problem is a periodic function which can be expressed as a Fourier series where the fundamental frequency $(f)$ is a function of engine rotational speed and the number of cylinders [29]. Therefore, the function of velocity and pressure $(P, v)$ that a particle situated at distance $x$ at time $t$ experienced, can be expressed generally as is shown in Eqs. (7) and (8) [2].

$P=P_{0}+\sum_{n=1}^{\infty} P_{n} \cdot \cos \left(2 \pi \cdot f \cdot n \cdot(x-c \cdot t)+\varphi_{P}\right)$

$v=v_{0}+\sum_{n=1}^{\infty} v_{n} \cdot \cos \left(2 \pi \cdot f \cdot n \cdot(x-c \cdot t)+\varphi_{v}\right)$

where $P_{0}, v_{0}$ are the average values, $P_{n}, v_{n}$ are the amplitude of each harmonic and $\varphi_{P}$ and $\varphi_{v}$ are the offset angles of the pressure wave and speed respectively.

\subsection{Mass flow rate measurement using pitot tubes}

Taking account the Mach number in a straight duct connected after the exhaust tail pipe of a conventional reciprocating combustion engine is much less than 0.3 , the exhaust flow can be considered macroscopically as steady one-dimensional incompressible flow [44]. Additionally, it is known, Pitot tube flow meters can measure the flow velocity in a steady incompressible flow by the Bernoulli equation, where differential pressure $\left(P_{D}\right)$ between stagnation point $\left(P_{T}\right)$ and static point $\left(P_{S}\right)$ is measured, knowing thermodynamics properties of the flow (temperature and density $\rho$ ) to obtain the flow velocity $(v)$ at measuring point, as shown in Eq. (9).

$v=k_{p} \cdot \sqrt{\frac{2\left(P_{T}-P_{S}\right)}{\rho}}=k_{p} \cdot \sqrt{\frac{2\left(P_{D}\right)}{\rho}}$

where $k_{P}$, is often called the Pitot constant with a value close to one when conventional Pitot tubes are used in dry air [15]. The Pitot constant depends on physical configuration of Pitot tube and it is determined empirically [9].

Because the Pitot type gas flow measurement depends on the square root of the differential pressure, as shown in Eq. (9), these flow meters have a serious accurate problem when dealing with pulsating flow, because average flow does not correspond with the flow calculated using the average differential pressure [36].

On the other hand, the velocity profile in a circular section of a tube is not flat due to the effects of boundary layer. If the flow is turbulent and fully developed [11], the velocity profile inside the tube tends to be flat, but if the flow is laminar (Reynolds number $<2300$ ) the velocity profile takes a curved shape with maximum speed in the middle of the tube, as shown in Fig. 1. In any case, the measured velocity with a Pitot tube in the center of

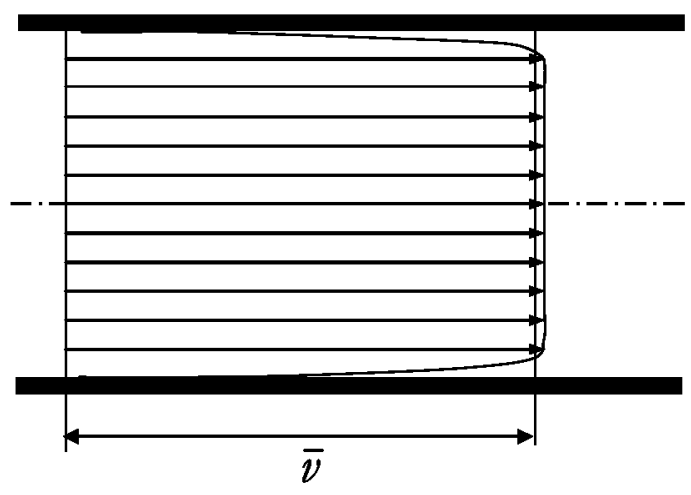

Turbulent flow

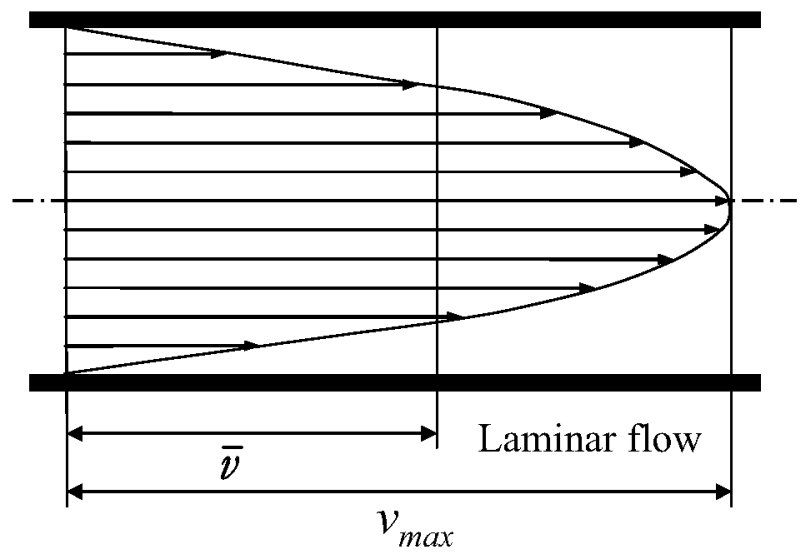

Fig. 1. Velocity profiles in a circular section tube for turbulent and laminar flow. 
the circular section is not equal to the average fluid velocity.

If the volume flow rate of a gas flow is to be measured with a Pitot tube located in the centre of the tube, the average flow velocity will be lower because of the boundary layers, and proportional to it. Thus, as shown in Eq. (10), the effects of the boundary layer effects and possible location and orientation defects are grouped in a factor $k_{H}$ that is experimentally determined in the calibration process $[15] \cdot[20]$.

$\bar{v}=k_{H} \cdot v$

And due to the fact that gas density could be written in terms on gas static pressure $\left(P_{S}\right)$, gas molecular mass $(M)$ and gas temperature $(T)$; average volume flow rate at actual conditions $\dot{V}$ (with cross-sectional area $A$ ) can be expressed as follows:

$\dot{V}=A \cdot k_{P} \cdot k_{H} \cdot \sqrt{\frac{2 \cdot P_{D}}{\rho}}=A \cdot K_{p i t o t} \sqrt{\frac{2 \cdot P_{D} \cdot R \cdot T}{P_{S} \cdot M}}$

where the $K_{\text {Pitot }}$ is a factor that takes into account the effect of the flow profile $\left(k_{H}\right)$ and the physical configuration of the Pitot tube $\left(k_{P}\right)$. And therefore, the mass flow rate could be calculated as shown in Eq. (12).

$\dot{m}_{E}=\dot{V} \cdot \rho=A \cdot K_{\text {pitot }} \sqrt{\frac{2 \cdot P_{D} \cdot P_{S} \cdot M}{\mathrm{R} \cdot T}}$

\subsection{Measurement of reverse flow with a pitot tube flow meter}

Despite the complexity, it has been demonstrated $[13,28]$ that Pitot type flow meters can be used for the measurement of reverse flow. Fig. 2 shows the behavior of a Pitot tube in a turbulent flow reverse condition. It has been noticed that at the entrance of a conventional Pitot tube a stagnation point is generated just at the midway point facing the flow, where the Eq. (9) is satisfactory. The aerodynamic contraction effect in the cross section of the Pitot tube causes an increase in flow velocity and thus a reduction in pressure, which is maintained along the Pitot tube until the end. At this point, a depression is generated and therefore a negative pressure drop.

In reverse turbulent flow, if the difference in pressure between the entrance of the Pitot tube $(P)$ (in Fig. 2) and the static pressure are measured in an area not affected by the disruption $\left(P_{0}\right)$, the differential pressure $\left(P_{D}\right)$ can be expressed as a function of the fluid velocity upstream, as shown in Eq. (13).

$P_{D}=P-P_{0}=-K_{\text {Pitot }}^{\prime} \cdot \frac{v_{0}^{2}}{2}<0$

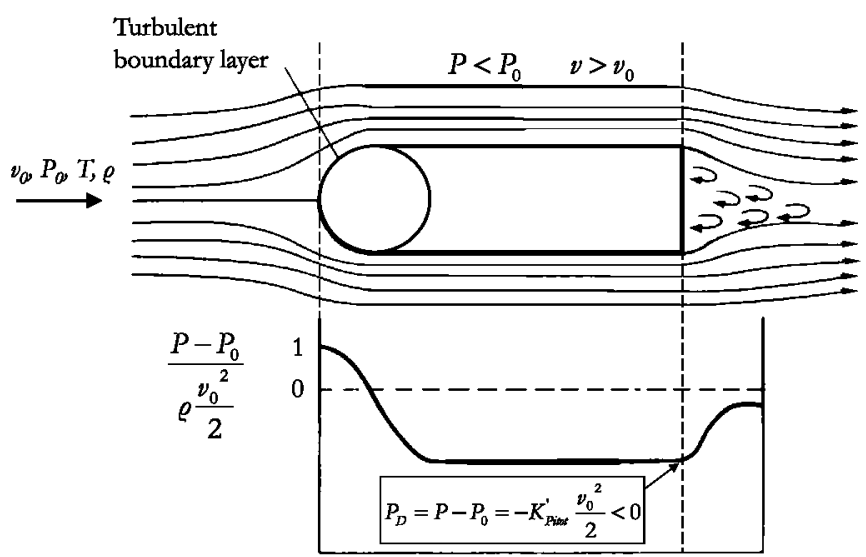

Fig. 2. Reverse flow scheme using Pitot tube in turbulent flow $R e>10^{5}$. Adapted from [7].
Therefore, under reverse flow it is likely that the behavior of Pitot tube can be expressed in terms of a different $K_{\text {Pitot }}^{\prime}$ factor, or at least not necessarily equal, to the Pitot factor in straight flow (Eq. (11)), as Pitot type flow meters patented by Horiba [28] and Cummins [13]. Therefore, the mathematical expression to calculate the inverse volume flow rate using a Pitot tube, is shown in Eq. (14). Where $K_{\text {Pitot }}^{\prime}$ factor must be experimentally determined in a calibration process.

$\dot{V}=-A \cdot K_{\text {Pitot }}^{\prime} \cdot \sqrt{\frac{2 \cdot\left|P_{D}\right| \cdot R \cdot T}{P_{S} \cdot M}}$

\section{Design of the pitot type MIVECO mass flow meter}

\subsection{Description}

Conventional Pitot tubes based on narrow tubes are designed to speed measurement in airplanes and any other types of aircrafts, but are inappropriate for measuring engine exhaust gas flow. Water droplets mixed with some particulate matter are formed by condensation of exhaust water content in the pressure ducts, mainly in spark ignition engines, including the narrow ducts and causing huge flow rate measurement errors. In order to tackle this problem, a new Pitot type flow meter, able to measure flow with high water and particle content, has been developed. The physical configuration of the Pitot type flow meter developed is shown in Fig. 3. To avoid the clogging at stagnation points, the stagnation pressure tube in the central axis has a diameter of $10 \mathrm{~mm}$ and is misaligned with the duct axial direction at an angle of $5^{\circ}$. It allows the drops of condensate water that may be formed to get out. Also, the static pressure is measured by three radial orifices on the duct inner surface connected to a pressure equalization crown, all in the same cross section as the stagnation point. Also a maintenance task injecting counter flow air from time to time to clean up drops formed within differential pressure lines is recommended, especially in the case of spark ignition engines in which water content in exhaust gases is higher than in diesel engines,

In order to improve the accuracy of the flow measurement and to ensure fully developed flow [40] both a minimum length of straight pipe upstream of flow meter position and a honeycomb straightener exhaust flow conditioner, formed by a bundle of tubes having the same length and diameter, were assembled as shown in Fig. 4, similar to the one develop by Gallagher et al. [11]. The straight length upstream the flow meter, excluded the honeycomb straightener, is about $640 \mathrm{~mm}$ that represent more than ten times the inside diameter, and the flow conditioner is $150 \mathrm{~mm}$ length, $60 \mathrm{~mm}$ internal diameter and the capillary tubes that form the

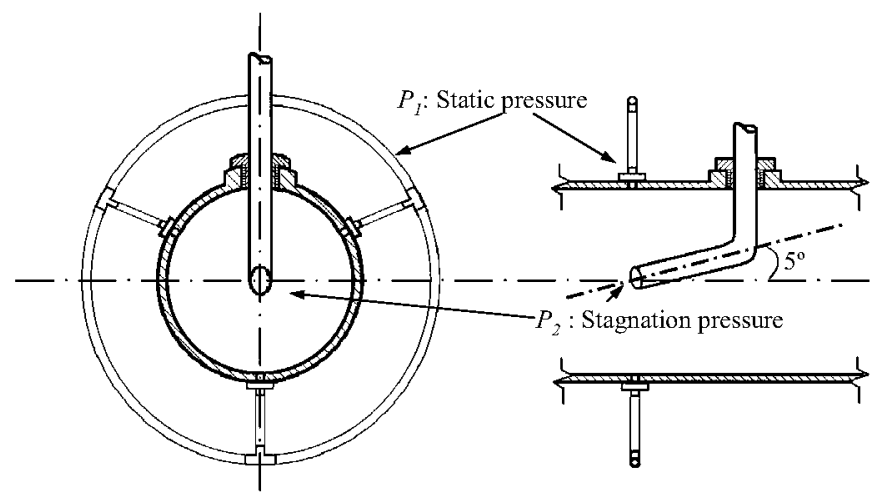

Fig. 3. MIVECO Pitot type mass flow meter 


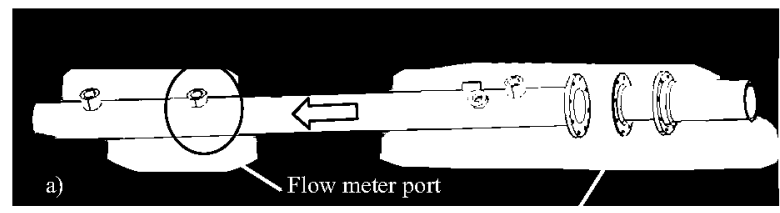

Straihtener honeycomb shaped
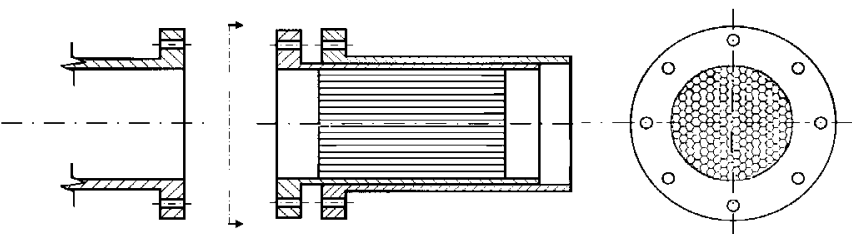

Fig. 4. Flow conditioner for Pitot type flow meter. (a) General configuration. (b) Honeycomb straightener detail.

bundle are $4 \mathrm{~mm}$ of diameter and $0.25 \mathrm{~mm}$ of thickness.

In order to be able to detect the pressure waves when idle, a differential pressure inductive transducer with short reaction time ( $\mathrm{T}_{90}$ approx. $0.02 \mathrm{~s}$ ) has been used, along with an exhaust gas temperature sensor $(T)$, an absolute pressure inductive transducer for static pressure $\left(P_{S}\right)$ measurement and an engine speed sensor to know the main frequency of the pulsation flow. In addition, an air-fuel ratio sensor $(\lambda)$ is used in order to determine the molecular weight of the exhaust gas using stoichiometric balance combustion equations, knowing fuel composition $\left(\mathrm{C}_{a} \mathrm{H}_{b} \mathrm{O}_{c}\right)$. For lean and rich combustion, molecular mass of exhaust gases ( $M_{\text {lean comb }}$ and $M_{\text {rich comb }}$ ) is calculated as shown in Eqs. (15) and (16), which for simplicity only takes into account the main species in the stoichiometry of the combustion reaction.

$$
\begin{gathered}
a \cdot M_{\mathrm{CO}_{2}}+\frac{b}{2} \cdot M_{\mathrm{H}_{2} \mathrm{O}}+3.773 \cdot \lambda \cdot\left(a+\frac{b}{4}-\frac{c}{2}\right) \cdot M_{\mathrm{N}_{2}} \\
M_{\text {lean_comb }}=\frac{+(\lambda-1)\left(a+\frac{b}{4}-\frac{c}{2}\right) \cdot M_{\mathrm{O}_{2}}}{a+\frac{b}{2}+3.773 \cdot \lambda \cdot\left(a+\frac{b}{4}-\frac{c}{2}\right)+(\lambda-1)\left(a+\frac{b}{4}-\frac{c}{2}\right)}
\end{gathered}
$$

$M_{\text {rich_comb }}=\frac{a \cdot M_{\mathrm{CO}_{2}}+e \cdot M_{\mathrm{H}_{2} \mathrm{O}}+3.773 \cdot \lambda \cdot\left(a+\frac{b}{4}-\frac{c}{2}\right) \cdot M_{\mathrm{N}_{2}}+i \cdot M_{\mathrm{H}_{2}}}{a+\frac{b}{2}+3.773 \cdot \lambda \cdot\left(a+\frac{b}{4}-\frac{c}{2}\right)}$

$e=c+2 \lambda \cdot\left(a+\frac{b}{4}-\frac{c}{2}\right)-2 a$

$i=\frac{b}{2}-e$

Recently, Akita et al. [1] have exposed a similar procedure in which lambda sensor is also used for accurate determination of molecular weight and density of the exhaust gases and therefore, for accurate measuring of mass flow rate.

\subsection{Calibration}

To determine the Pitot factor in straight flow $\left(K_{\text {Pitot }}\right)$, a centrifugal blower and a MERIAM Laminar Flow meter model $50 \mathrm{MH} 10-3 \mathrm{NT}$ (nominal air flow range at $760 \mathrm{~mm} \mathrm{Hg}$. and $21.1^{\circ} \mathrm{C}$ is $0-2.7 \mathrm{~m}^{3} / \mathrm{min}$; accuracy $=0.64 \%$ of actual reading) was used with a method similar to one presented by Colvin I6l. The Meriam Laminar Flow Element (LFE) was used because this kind of flow meters is inherently accurate and repeatable and is calibrated traceable to NIST [24]. The calibration was done with fresh air in steady flow condition and the laminar flow meter temperature correction was taken into account. The measurement conditions were ambient temperature $20^{\circ} \mathrm{C}$ and atmospheric pressure of $94 \mathrm{kPa}$. The calibration was done directly in mass flow unit $(\mathrm{g} / \mathrm{s})$

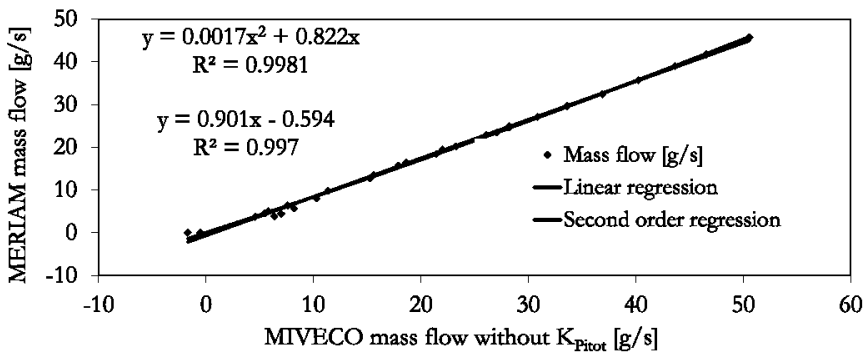

Fig. 5. Calibration of MIVECO mass flow meter in steady state air with direct flow.

for 30 different flow rates, that were adjusted by a flow control valve, and where left to determine the Pitot factor $\left(K_{\text {Pitot }}\right)$. The calibration curve is shown in Fig. 5, where the linear regression equation with a correlation factor of 0.997 and a better correlation of the second order with a $R^{2}=0.9981$ are included. Although the second order correlation fits better because of the compressibility of the fluid, the linear approximation suits well enough for mass flow rates up to $50 \mathrm{~g} / \mathrm{s}$. Therefore, from the linear regression function obtained in the calibration curve, it follows that the Pitot factor $\left(K_{\text {Pitot }}\right)$ can be calculated as a function of the "MIVECO mass flow without $K_{\text {Pitot }}$, defined in Eq. (17) based on Eq. (12), as shown in Eq. (18).

$\dot{m}_{E}=K_{\text {pitot }} \cdot A \cdot \sqrt{\frac{2 \cdot P_{D} \cdot P_{S} \cdot M}{\mathrm{R} \cdot T}}=K_{\text {pitot }} \cdot \dot{m}_{E_{-} \text {without_K }}$

$K_{\text {pitot }}=0.901-\frac{0.594}{\dot{m}_{E_{-} \text {without_K }}}$

The calibration with reverse flow was performed in the same manner but placing the flow meter as opposed to the flow. In Fig. 6 the calibration data is shown. It can be shown that the Pitot factor in reserve flow is larger than in direct flow and also the influence of compressibility is greater.

\subsection{Flow meter validation with pulsating flow}

In order to validate the measurement of pulsating flow, the arrangement shown in Fig. 7 was performed. Two passenger cars equipped one with a $1100 \mathrm{~cm}^{3}$ displacement spark ignition engine and the other with a $2000 \mathrm{~cm}^{3}$ displacement diesel engine were used for this test. MIVECO flow meter was fitted at the end of the each exhaust tail pipe to measure the oscillatory flow. The reference flow meter was a MERIAM Laminar Flow meter model Z50MH10-2 (nominal air flow range $760 \mathrm{~mm} \mathrm{Hg}$. and $21.1^{\circ} \mathrm{C}=1.2 \mathrm{~m}^{3} / \mathrm{min}$; accuracy $=0.64 \%$ of actual reading) connected downstream of a surge tank to absorb pressure and flow waves.

For this test, a $1 \mathrm{kHz}$ data acquisition frequency was used in order to meet the Nyquist-Shannon sampling theorem, which states that the minimum sampling frequency should be twice the maximum frequency of the signal to be measured. Fig. 8 shows the observed mass flow rate measures at idle for the two passenger

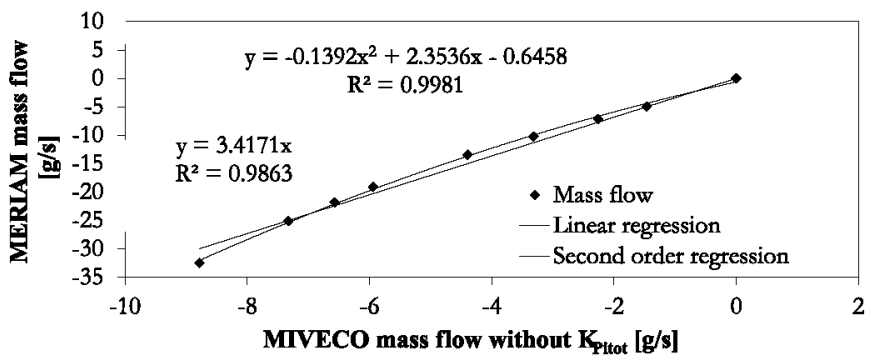

Fig. 6. Calibration of MIVECO mass flow meter in steady state air with reverse flow. 


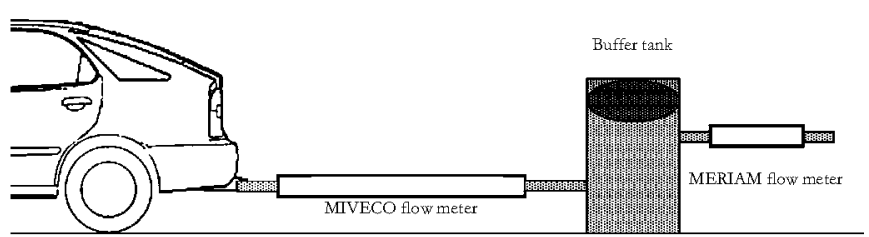

Fig. 7. Assembly used to validate the MIVECO mass flow meter with pulsating flow.

cars, the average flow measured using the reference laminar flow meter and the instantaneous pulsating mass flow rate using the MIVECO flow meter.

The measurement conditions of the tests presented in Fig. 8 are shown in Table 1.

In order to compare the average mass flow rate measured by the MIVECO flow meter at $1 \mathrm{kHz}$ with the average mass flow rate measured by the reference laminar flow meter (MERIAM), several tests were done on the two cars at unloaded conditions from idle to $4000 \mathrm{~min}^{-1}$. Comparison of these mass flow rate measurements are shown in Fig. 9. The MIVECO flow meter adjustment is very good.

Once the MIVECO flow meter was calibrated in stationary conditions, and their ability verified to measure oscillatory flow at a sampling frequency of $1 \mathrm{kHz}$, more thorough tests were done in order to explore the oscillatory nature of the exhaust gas flow under varying conditions of the engine.

These tests were performed with a 4 -cylinder $2100 \mathrm{~cm}^{3}$ turbocharged diesel engine passenger car on a chassis dynamometer. In order to measure the full-wave oscillation of exhaust gases from this engine, a sampling frequency of $1 \mathrm{kHz}$ was used. The exhaust volume flow rate was calculated at $1 \mathrm{kHz}$ using Eqs. (11) and (14) and the calibration factors previously determined $\left(K_{\text {Pitot }}\right.$ and $\left.K_{\text {Pitot }}^{\prime}\right)$, considering that the factor $K_{\text {Pitot }}$ used is the corresponding to the average flow, not to the instantaneous flow. The test was conducted initially at idle and at different engine speeds $\left(2000 \mathrm{~min}^{-1}\right.$. $3000 \mathrm{~min}^{-1}$ and $4000 \mathrm{~min}^{-1)}$ and then at different vehicle constant speeds (idle, 40, 60, 80 and $100 \mathrm{~km} / \mathrm{h}$ ). The results can be seen in Figs 10 and 11 respectively.

As is shown in Figs. 10 and 11, exhaust flow oscillation at idle is high and significant amount of backward flow is observed as in Nakamura et al. [29] results, while in the others operating conditions pulsating phenomenon is much less significant. Similar results were found in a 4-cylinder spark ignition engine passenger car also tested on chassis dynamometer.

These results confirm that exhaust flow at idle is a periodic phenomenon that can be expressed as Eqs. (7) and (8). In addition, it is observed that the wave's main frequency is directly related to the frequency of individual cylinder exhaust process as mentioned above, verifying that the wave frequency is equal to twice the engine rotational speed in a four-stroke 4-cylinder engine. Therefore, regardless of the phase angle between the exhaust flow wave and lift movement of the exhaust valves, differential pressure and exhaust flow waves equations for a 4-cylinder and fourstroke engine are shown as Eqs. (19) and (20), where $n$ engine speed is in $\left(\mathrm{sec}^{-1}\right), P_{D m}$ and $V_{m}$ are pressure and flow wave amplitude respectively and $P_{D_{-} o}$ and $V_{m_{-} 0}$ are the offset pressure and volume flow rate value respectively.

$P_{D}=P_{D m} \cdot \sin (4 \pi \cdot n \cdot t)+P_{D \_0}$

$\dot{V}=\dot{V}_{m} \cdot \sin (4 \pi \cdot n \cdot t)+\dot{V}_{m \_0}$

\section{Methodology for the determination of the instantaneous average exhaust mass flow rate with the MIVECO flow meter}

\subsection{Exhaust flow sampling and data recording frequencies for PEMS}

Tests about transient conditions measurement in light duty vehicles with PEMS, done previously by the authors, show that the minimum sampling frequency for emissions concentration and exhaust flow measurement should be $9 \mathrm{~Hz}$ [10]. Therefore, data recording frequency of $10 \mathrm{~Hz}$ was considered high enough to fully appreciate the transients that occur in real traffic and low enough to have moderate size test data files. Taking into account, that the sampling frequency at $1 \mathrm{kHz}$ is adequate to observe the actual oscillation of exhaust gas flow (see Fig. 11), different methods to calculate and record exhaust flow at $10 \mathrm{~Hz}$ had been compared.

The first method was realized by sampling the differential pressure at $10 \mathrm{~Hz}$ and computing the exhaust flow at that frequency, as shown in Fig. 12 as "Instantaneous Flow measured at $10 \mathrm{~Hz}$. It can be seen that this way is not useful because the amplitude of the measured signal equals that of the actual flow wave amplitude, but at lower frequency. It retains the strong oscillation, which cannot be used later to determine the average volume flow rate because of the "square root error", caused by nonlinear relationship between differential pressure and flow, as is widely discussed by Nakamura et al. [29]. Such measurement errors can be clearly seen in the development of other exhaust gas flow meters $([16,17,19,29])$, where negative flow values are also observed.

The second way was done by calculating the volume flow rate at $10 \mathrm{~Hz}$ based on the differential pressure signal (measured at $1 \mathrm{kHz}$ ) averaged at $10 \mathrm{~Hz}$, as shown in Fig. 12 as "Wrong average at $10 \mathrm{~Hz}$ ". This way of volume flow rate measurement is wrong due to the "square root error" discussed before. The third way was done by calculating the average flow at $10 \mathrm{~Hz}$, based on instantaneous volume flow rate calculated at $1 \mathrm{kHz}$ using instantaneous differential pressure measured a $1 \mathrm{kHz}$, as shown in Fig. 12 as "Real average at $10 \mathrm{~Hz}$. This latter method of measuring the exhaust flow is correct, but it still shows some oscillation, but a lower frequency and with lower amplitude.

\subsection{Proposed methodology to determine the average exhaust mass flow rate for PEMS use}

Due to the complexity in determining and recording average exhaust gas flow data at idle, many researchers and PEMS manufacturers have chosen to use, in these conditions, a fixed volume

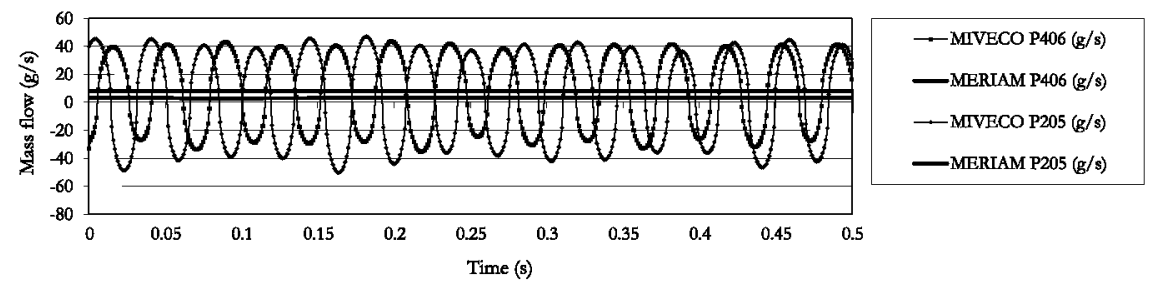

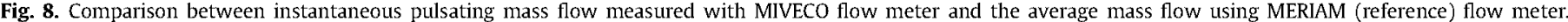
$2000 \mathrm{~cm}^{3}$ diesel tourism (P406) and gasoline tourism $1100 \mathrm{~cm}^{3}(\mathrm{P} 205)$. 
Table 1

Conditions of measurement data presented in Fig. 8.

\begin{tabular}{|c|c|c|c|c|c|c|}
\hline Vehicle & $\begin{array}{l}\text { Engine speed } \\
\left(\min ^{-1}\right)\end{array}$ & $\begin{array}{l}\text { Exhaust flow temperature } \\
\text { MIVECO }\left({ }^{\circ} \mathrm{C}\right)\end{array}$ & $\begin{array}{l}\text { Exhaust flow temperature } \\
\text { MERIAM }\left({ }^{\circ} \mathrm{C}\right)\end{array}$ & $\begin{array}{l}\text { Lambda factor } \\
\lambda\end{array}$ & $\begin{array}{l}\text { Ambient temperature } \\
\left({ }^{\circ} \mathrm{C}\right)\end{array}$ & $\begin{array}{l}\text { Actual pressure. } \\
(\mathrm{Pa})\end{array}$ \\
\hline $\begin{array}{l}\text { Diesel } 2000 \mathrm{~cm}^{3} \\
\quad(\mathrm{P} 406)\end{array}$ & 821.4 & 37.2 & 32.5 & 5.01 & 27.7 & 93,906 \\
\hline $\begin{array}{l}\text { Gasoline } 1100 \mathrm{~cm}^{3} \\
(\mathrm{P} 205)\end{array}$ & 859.3 & 51.4 & 39.1 & 1.03 & 26.5 & 93,939 \\
\hline
\end{tabular}

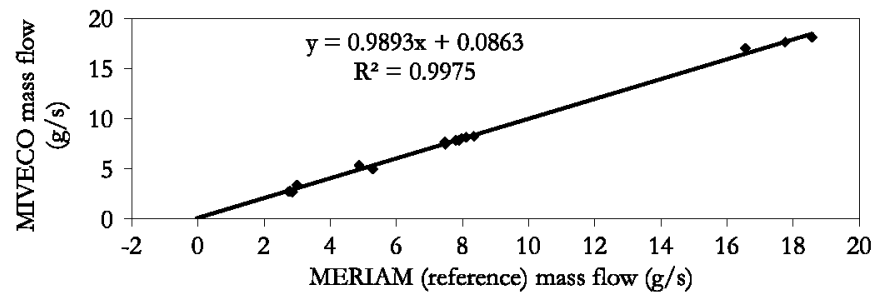

Fig. 9. Validation of MIVECO average mass flow rate measured at $1 \mathrm{kHz}$.

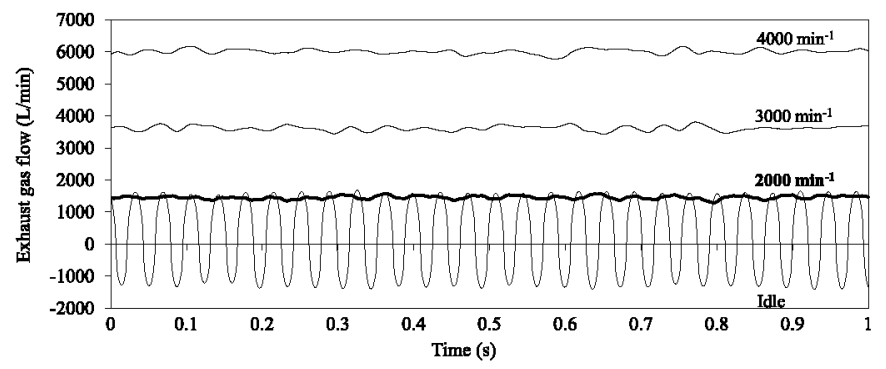

Fig. 10. Instantaneous flow of exhaust gases at idle conditions. 4-cylinder turbocharged diesel engine $2000 \mathrm{~cm}^{3}$.

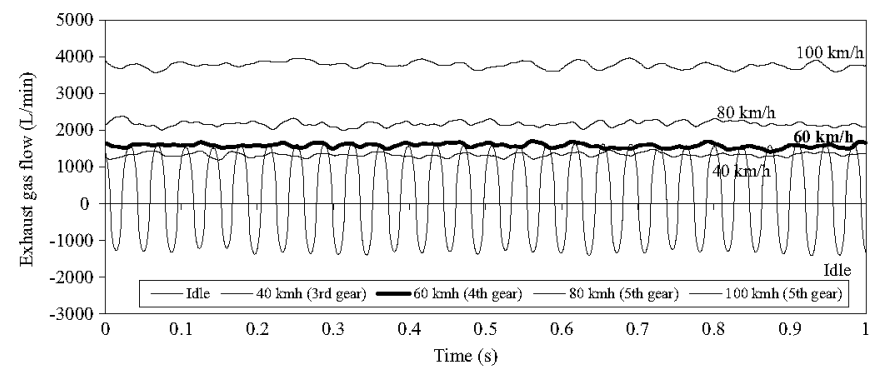

Fig. 11. Instantaneous flow of exhaust gases at constant speed. 4-cylinder turbocharged diesel engine $2000 \mathrm{~cm}^{3}$.

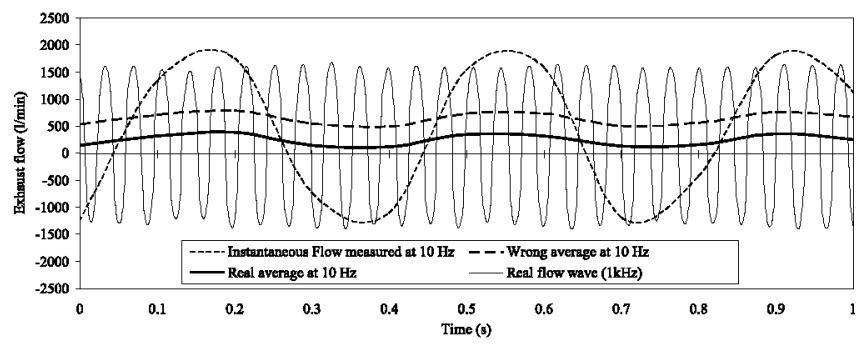

Fig. 12. Effect of calculation and recording frequency on exhaust gas flow signal at idle engine conditions.

flow rate value determined previously [28]. Other researchers have developed different methods for measuring average exhaust flow to be used in PEMS, like Nakamura [31], in which buffer tanks in conjunction with a moving average are used to attenuate the oscillation of the pressure waves at the differential pressure sensor inlet in order to compensate the "square root error" and maintaining the sampling frequency at $10 \mathrm{~Hz}$. And thus be able to determine the average exhaust volume flow rate with enough precision.

A year later, Horiba presented another patent, in which the buffer tank is not used, but uses another methodology in which the differential pressure signal is accumulating in a data buffer. This signal is then resolved in frequency in order to apply a correction coefficient for each frequency component. The average volume flow rate is then calculated using the differential pressure signal measured and the different correction coefficients experimentally found [28].

As it has been said before, in the Pitot type exhaust flow meter the most important instrument is the differential pressure sensor; small zero setting errors in the differential pressure measure, overcome in significant errors in the calculated volume flow rate. In addition, it is a fact that the measurement accuracy at very low volume flow rate strongly influences the calculation of the emissions and the fuel consumption factors in real urban traffic, where significant periods of time with the engine at idle are frequent [10].

It is important to note that, according to the other developed methodologies to determinate the average exhaust flow [28], it is not possible to correct (off-line) the lack of synchronization or other errors that may occur in the differential pressure or any other signal instrument during the tests. Some of the most common errors are zero adjustment or hysteresis errors that often occur with standard specifications pressure sensors, because with those methodologies, the instantaneous data at high frequency is not recorded. This causes one of the most significant accuracy problems involved in emissions measurement testing in real traffic with PEMS.

Therefore, a methodology for off-line calculating of the instantaneous averaged exhaust gas mass flow rate, using real time measurement at $1 \mathrm{kHz}$ of the static and differential pressure signals and the other variables involved, has been developed. It is based on recorded at $10 \mathrm{~Hz}$ the variability present in the all variable signals involved, using conventional instrumentation and conventional data acquisition, processing and data storage system. This methodology let to correct some signal common errors such as lack of synchronization and zero drift. Also, recording data at $10 \mathrm{~Hz}$ enables lighter management data.

The developed methodology is based on the fact that differential pressure wave can be approximated to a perfect sine wave, as shown in Fig. 8 and in Eq. (19), where the fundamental frequency of the flow wave is equal to twice the engine speed for 4 cylinders and 4 -stroke engines [29]. In this way, the differential pressure wave is completely defined by its offset value $\left(P_{D_{-} o}\right)$, amplitude $\left(P_{D m}\right)$ and frequency $(2 \cdot n)$. The methodology involve such differential pressure offset value $\left(P_{D_{-}}\right)$at each $0.1 \mathrm{~s}(10 \mathrm{~Hz})$ calculated as the average of the instantaneous differential pressure measured at $1 \mathrm{kHz}$ (100 samples). Amplitude is indirectly measured as its standard deviation and the frequency is measured as engine speed using a magnetic vibration sensor tachometer. In this way, differential pressure is sampled at $1 \mathrm{kHz}$, but only the offset value and standard deviation of this signal are recorded at $10 \mathrm{~Hz}$, adding engine speed signal recorded also at $10 \mathrm{~Hz}$. Thus, the 


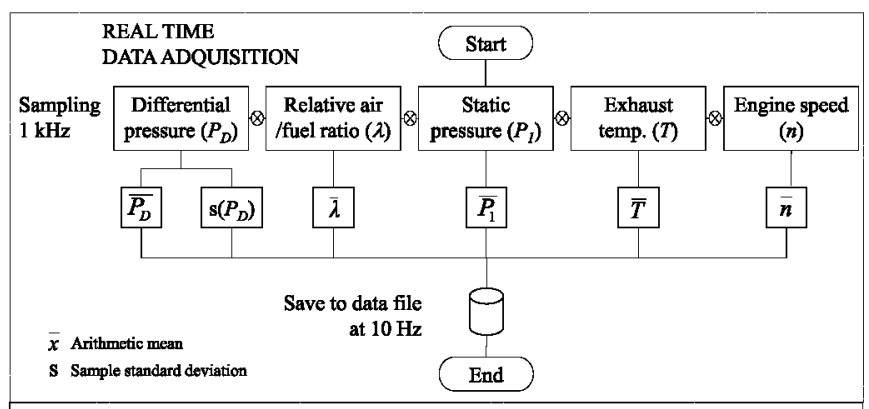

DATA POSTPROCESSING

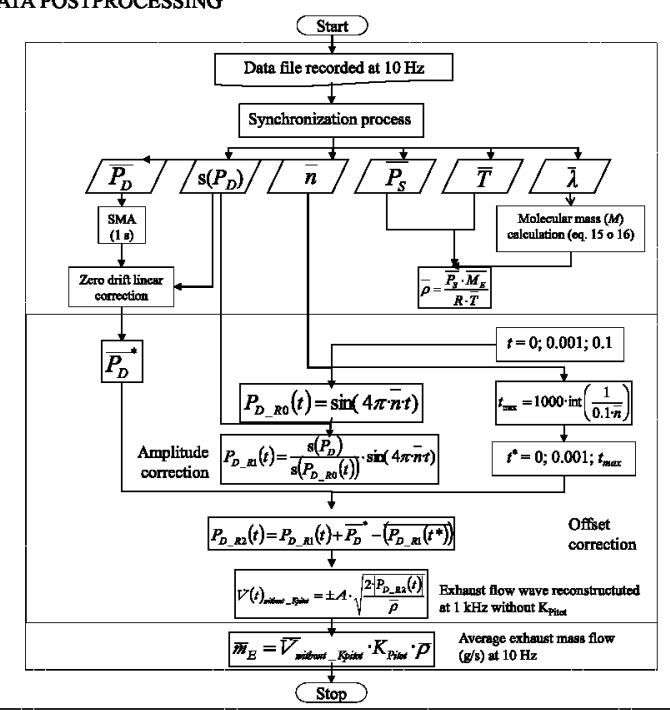

Fig. 13. Methodology for instantaneous average measurement of exhaust mass flow, using the MIVECO flow meter.

proposed methodology is based on the possibility of reconstruction of the differential pressure wave knowing the offset value, standard deviation and the natural frequency. The methodology for calculating the average exhaust flow consists in several steps, as shown in Fig. 13.

The methodology has two parts: real time data acquisition and data post-processing. Data averaging is made for each signals: differential pressure $\left(P_{D}\right)$, engine speed $(n)$, static pressure $\left(P_{S}\right)$, exhaust temperature $(T)$ and relative air/fuel ratio $(\lambda)$; and differential pressure standard deviation $\left(s\left(P_{D}\right)\right)$ is recorded in order to retain the amplitude of differential pressure oscillations as mentioned above.

Data post-processing is done off-line using the files recorded in data acquisition process. First of all, the stored signals are synchronized; then, average molecular weight (Eq. (15) or Eq. (16)) and average density are calculated at $10 \mathrm{~Hz}$ as shown in Fig. 13. Simple Moving Average (SMA) is applied for differential pressure recorded at $10 \mathrm{~Hz}$ in a moving window of $1 \mathrm{~s}$, in order to correct the error caused by not using an integer number of complete wave periods for calculating the average at $10 \mathrm{~Hz}$, deleting the signal ripple.

After that, a zero drift linear correction is made for the differential pressure signal based on the differential pressure signal measured value at the beginning and at the end of each test, when the exhaust gas flow is zero (engine off), obtained the corrected average differential pressure signal $\left(\bar{P}_{D}^{*}\right)$.

In order to reconstruct the differential pressure wave in time domain, a sine wave with a frequency equal to twice the engine speed in an interval of 0.1 is firstly constructed using sampling time of $1 \mathrm{~ms}$, taking into account that the engine is a 4-cylinder and four-stroke (Eq. (19)). After that, amplitude correction is done based on the relation between differential pressure standard deviation recorded in the acquisition file and the standard deviation of the sine wave generated. Offset correction is calculated as the difference between $\bar{P}_{D}{ }^{*}$ and the average of the amplitude corrected differential pressure wave $\left(\overline{P_{D-R 1}\left(t^{*}\right)}\right)$, taking in account only the maximum number of wave periods that fall within $0.1 \mathrm{~s}$, therefore $t^{*}=0: 0.001: t_{\max }$, where $t_{\max }$ is calculated as shown in Fig. 13. It is considered an integer of periods to eliminate the unreal ripple that occurs when averaging at $10 \mathrm{~Hz}$.

After that, gas volume flow without $K_{\text {Pitot }}$ is calculated at $1 \mathrm{kHz}$ as Eqs. (11) and (14), depending on the sign of the differential pressure. The average exhaust mass flow rate without $K_{\text {Pitot }}$ is calculated at $10 \mathrm{~Hz}$ taking into account only the maximum number of complete wave periods that fall within the $0.1 \mathrm{~s}$ period, and finally, because the viscous forces act on the mean flow, not on the pulsation, the average exhaust mass flow rate is calculated using the $K_{\text {Pitot }}$ corresponding to this average exhaust mass flow rate, as is shown in Fig. 13.

Comparison between a measured differential pressure wave and the reconstructed pressure wave according to the methodology presented is shown in Fig. 14. Good similarity between the waves is observed, although the measured wave is not perfectly regular.

\subsection{Discussion about influencing factors}

As has been shown in Fig. 14, the waveform of the differential pressure signal is a sine-wave-like. However, as any wave, it could suffer distortion phenomena such as diffraction or interference. Therefore, a study of the influencing factors that may deviate from this assumption and deteriorate the estimation precision has been made.

In real driving emission testing the mass flow meter requires the use of extension ducts upstream and downstream, as shown in Fig. 15. Thus, a study about the effect of the length and curvature of the extension tube on the mass exhaust flow measurement was made. $2000 \mathrm{~cm}^{3}$ turbocharged diesel vehicle was used, with different lengths for downstream extension tubes (after flow meter). The tests were made at idle $\left(823.6 \pm 3.8 \mathrm{~min}^{-1}\right)$, because the pulsation phenomenon occurs mainly in this engine condition. The results are presented in Table 2.

Table 2 shows that the curvature of the downstream duct does not affect significantly either the differential pressure wave neither the average exhaust gas mass flow measured instantaneously. Nevertheless, the length of the extension duct downstream has a significant effect over the amplitude and the mean value of the wave registered at $10 \mathrm{~Hz}$ (measured as the mean value and standard deviation of the differential pressure signal measured at $1 \mathrm{kHz}$ ), although the effect over the instantaneous average exhaust gas mass flow measured is slight. These tests show that the error induced by these accessories is less than $0.2 \%$ of full scale.

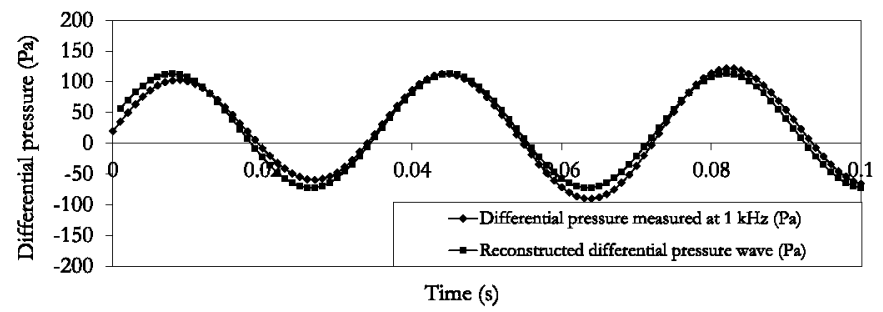

Fig. 14. Differential pressure wave. Comparing actual measured wave and reconstructed wave. $2000 \mathrm{~cm}^{3}$ diesel engine Tourism at idle. 


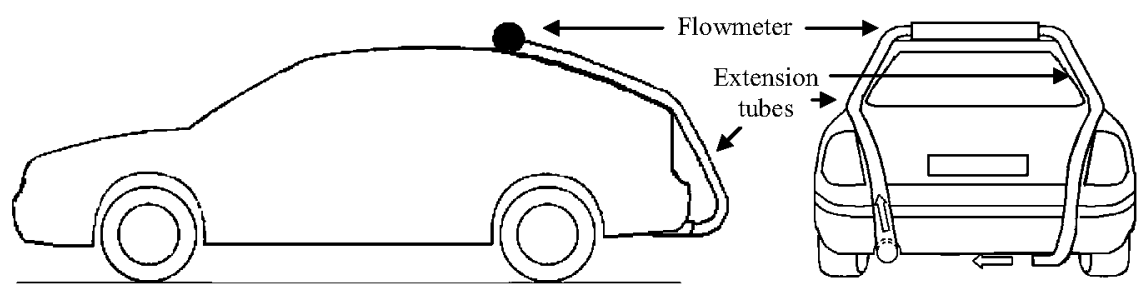

Fig. 15. Installation of the flow meter in a light duty vehicle.

Table 2

Effect of downstream extension tube on differential pressure wave.

\begin{tabular}{|c|c|c|c|c|c|c|c|}
\hline \multirow[t]{2}{*}{ Test no. } & \multicolumn{2}{|c|}{ Extension tube } & \multicolumn{2}{|c|}{$\begin{array}{l}\text { Differential pres- } \\
\text { sure }\left(P_{D}\right) \text { re- } \\
\text { corded at } 10 \mathrm{~Hz} \\
(\mathrm{~Pa})\end{array}$} & \multirow[t]{2}{*}{$\begin{array}{l}\text { Mass } \\
\text { flow } \\
(\mathrm{g} / \mathrm{s})\end{array}$} & \multirow[t]{2}{*}{$\begin{array}{l}\mathrm{SD} \text { of } \\
\text { mass } \\
\text { flow } \\
(\mathrm{g} / \mathrm{s})\end{array}$} & \multirow[t]{2}{*}{$\begin{array}{l}\text { Error } \\
\text { FE } \\
(125 \mathrm{~g} / \\
\mathrm{s})\end{array}$} \\
\hline & Length (m) & Curvature & $\begin{array}{l}\text { Mean } \\
\text { over } \\
60 \mathrm{~s}\end{array}$ & $\begin{array}{l}\text { SD } \\
\text { over } \\
60 \mathrm{~s}\end{array}$ & & & \\
\hline 1 & 3.6 & $180^{\circ}$ & 7.4 & 119.0 & 2.10 & 0.25 & $0.04 \%$ \\
\hline 2 & 3.6 & $0^{\circ}$ & 7.7 & 124.0 & 2.20 & 0.26 & $0.12 \%$ \\
\hline 3 & 3.6 & $30^{\circ}$ & 7.7 & 132.0 & 2.27 & 0.32 & $0.17 \%$ \\
\hline 4 & $0^{\mathrm{a}}$ & $0^{\circ}$ & 6.6 & 18.0 & 2.05 & 0.17 & REF \\
\hline
\end{tabular}

${ }^{a}$ Without extension tube as calibrated.

\section{Validation results}

In order to validate and to determine the performance (accuracy, repeatability and noise) of the MIVECO averaged exhaust flow meter, some tests were done based on the standard procedure in the regulations 40 CFR 1065.305 and conducted on chassis dynamometer using similar methodology to that presented by Booker [4]. The Horiba OBS-2200, an on-board portable emission measurement system (PEMS) verified according with CFR part 1065 [30], as the reference and a $2000 \mathrm{~cm}^{3}$ diesel engine passenger car were used in the validation test. Horiba OBS-2200 uses a Pitot type flow meter ref PTFM-1000-D with nominal air flow range at $760 \mathrm{~mm} \mathrm{Hg}$. and $293.15 \mathrm{~K}$ of $15 \mathrm{~m}^{3} / \mathrm{min}$ (accuracy $=1.5 \%$ of full scale). The comparison was done in mass flow rate values, because the temperature and the static pressure of the exhaust gas are not equal in the two flow meters series connected.

\subsection{MIVECO flow meter performance in steady conditions}

Noise, defined according to 40 CFR 1065.305 standard [45], is twice the root-mean-square of the ten values of standard deviations (that is, noise $=2 \cdot \mathrm{rms} \sigma$ ) when the reference signal is a zeroquantity signal. To determine the noise, 10 intervals of $30 \mathrm{~s}$ from the start of each of the tests performed on the chassis dynamometer were taken into account, since all tests were started with the engine off and exhaust gas flow is zero. Noise of MIVECO mass flow meter results is shown in Table 3.

Accuracy, according to 40 CFR 1065.305 standard, is defined as the absolute difference between the reference quantity, $y_{\text {ref }}$, and the arithmetic average of the ten $y$ values. Intervals of 30 s were chosen, wherein the reference value during the time interval remains constant, as is shown in Fig. 16. The result of the accuracy is

Table 3

Noise of MIVECO mass flow meter.

\begin{tabular}{lllll}
\hline noise $=2 \cdot r m s_{\sigma}(\mathrm{g} / \mathrm{s})$ & $\begin{array}{l}\text { Full Scale } \\
(\mathrm{g} / \mathrm{s})\end{array}$ & noise \% FS & $\begin{array}{l}\text { max noise \% FS } 40 \\
\text { CFR 1065-J }\end{array}$ & Compliance \\
\hline 0.9926 & 125 & $0.8 \%$ & $1 \%$ & Yes \\
\hline
\end{tabular}

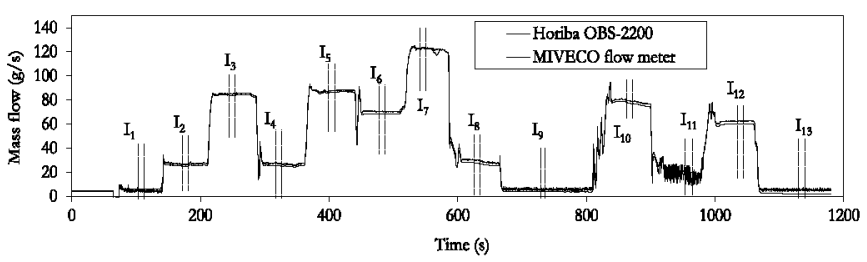

Fig. 16. Validation test: intervals to determine the accuracy and repeatability of Miveco flow meter.

shown in Table 4.

Repeatability, according to 40 CFR 1065.305 standard, is twice the standard deviation of the ten errors (that is, repeatability $=2$. $\sigma_{\varepsilon}$ ). The validation test used was the same as the one used for accuracy determination (Fig. 16), and the results are shown in Table 5 .

\subsection{Final transient validation}

The final validation tests were done following the New European Driving Cycle NEDC using a $2000 \mathrm{~cm}^{3}$ diesel engine passenger car and an $1100 \mathrm{~cm}^{3}$ gasoline engine passenger car as shown in Figs. 17 and 18, respectively.

In the NEDC validation tests done with the diesel car, the average instantaneous error was $-1.12 \%$ FSO with a standard deviation of $1.53 \%$ and the error accumulated at the end of the NEDC test was $4.53 \%$. On the other hand, in the validation test with the gasoline car, the instantaneous error average was $-0.32 \% \mathrm{FSO}$ with a standard deviation of $2.2 \%$ and accumulated error at the end of the NEDC test was $3.8 \%$. Furthermore, more than $170 \mathrm{~h}$ and more than $1550 \mathrm{~km}$ of tests have been performed to measure actual emissions in urban traffic, with petrol and diesel engine vehicles. It has been demonstrated that the MIVECO flow meter performs properly as part of a Portable Emission Measurement System (PEMS), without any problems of clogging by moisture or particles.

\section{Conclusions}

In this paper a methodology for developing a flow meter for instantaneous average exhaust mass flow rate measuring in reciprocating internal combustion engines of vehicles is presented. The methodology for calibration and validation would be useful for researchers involved in similar developing tasks.

Regarding the developed MIVECO mass flow meter, the following conclusions have been obtained:

Table 4

Accuracy of MIVECO mass flow meter.

\begin{tabular}{lllll}
\hline Accuracy $=\frac{\sum_{i=1}^{13}\left|\bar{y}_{i}-\bar{y}_{r e f-i}\right|}{13}(\mathrm{~g} / \mathrm{s})$ & $\begin{array}{l}\text { Full } \\
\text { scale } \\
(\mathrm{g} / \mathrm{s})\end{array}$ & $\begin{array}{l}\text { Accuracy } \\
(\% \mathrm{FS})\end{array}$ & $\begin{array}{l}\text { Maximun \% } \\
\text { FS CFR } \\
1065-\mathrm{J}\end{array}$ & Compliance \\
\hline 1.7 & 125 & $\mathbf{1 . 4 \%}$ & $4 \%$ & Yes \\
\hline
\end{tabular}


Table 5

Repeatability of MIVECO mass flow meter.

\begin{tabular}{lllll}
\hline Repeatability $=2 \sigma_{E}(\mathrm{~g} / \mathrm{s})$ & $\begin{array}{l}\text { Full } \\
\text { Scale } \\
(\mathrm{g} / \mathrm{s})\end{array}$ & $\begin{array}{l}\text { Repeatability } \\
(\% \mathrm{FS})\end{array}$ & $\begin{array}{l}\text { Maximun \% } \\
\text { FS 40 CFR } \\
1065-\mathrm{J}\end{array}$ & Compliance \\
\hline 1.07 & 125 & $0.9 \%$ & $2 \%$ & Yes \\
\hline
\end{tabular}

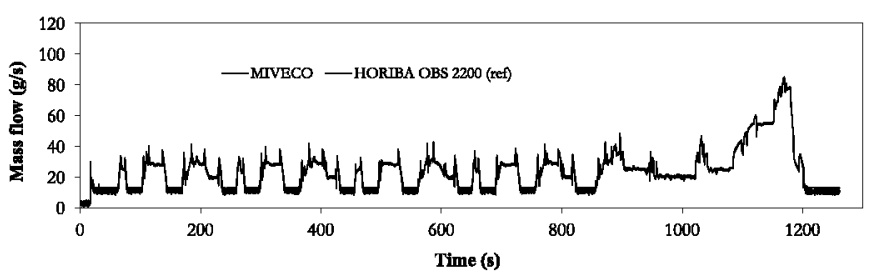

Fig. 17. Validation test: New European Driving Cycle. $2000 \mathrm{~cm}^{3}$ diesel engine Tourism.

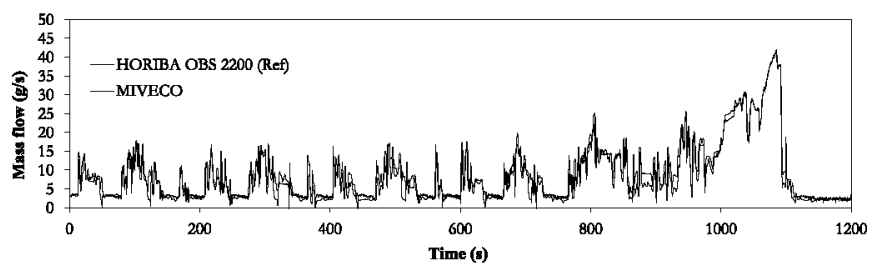

Fig. 18. Validation test: NEDC cycle. $1100 \mathrm{~cm}^{3}$ gasoline engine Tourism.

- It has been found that the configuration of the MIVECO Pitot type flow meter, developed for measuring exhaust gas mass flow rate in PEMS, is appropriate because clogging with moisture and/or particles is avoided.

- The developed mass flow meter is able to measure the average exhaust gas flow emitted by a reciprocating internal combustion engine during low speed periods, even when instantaneous backflow occurs.

- The off-line methodology developed to determine the average exhaust gas mass flow rate of an engine is suitable and it meets the USA standard for flow meters used as part of PEMS (40 CFR 1065.305 ) since the accuracy is better than $1.5 \% \mathrm{FSO}$, noise is less than $1 \%$ FSO and repeatability equals to $0.9 \%$ FSO. In the chassis dynamometer validation following the NEDC cycle, shows that the instantaneous error is less than $2 \%$ FSO and accumulated error throughout the entire cycle NEDC is less than $5 \%$

\section{Acknowledgments}

The authors would like to acknowledge the financial support for this project provided by the Ministry of Environment and Rural and Marine Affairs of Spain (Grant number 071/2006/3-13.2). The authors also wish to acknowledge the help to perform the validation tests to the University Institute for Automobile Research INSIA and the contributions of David Nieto and Victor Pozo carrying out the tests.

\section{References}

[1] M. Akita, H. Nakamura, I. Asano, M. Adachi, Fuel consumption calculation unit, fuel consumption measuring apparatus, and exhaust gas measuring apparatus. U.S. Patent 2015/0046101 A1, 2015.

[2] W.J.D. Annand, G.E. Roe, Gas Flow in the Internal Combustion Engine: Power Performance, Silencing and Emission Control, GT Foulis \& Co. Ltd., England, 1974 (ISBN: 0854291601).
[3] M. Beck, K. Hinterhofer, Direct high dynamic flow measurement in the exhaust of combustion engines, SAE International Journal of Engines, Paper Number 980880, 1998. Doi: http://dx.doi.org/10.4271/980880.

[4] Booker Dr. Method for internal combustion engine exhaust flow measurement calibration and operation. U.S. Patent 2015/0143869 A1, 2015.

[5] L.A.G. Breton, Real-time on-road vehicle exhaust gas modular flow meter and emissions reporting system, U.S. Patent 6,148,656 A, 2000.

[6] A. Colvin, J. Butler, T. Korniski, Portable vehicle exhaust flow sensor. U.S. Patent $7,568,383$ B2, 2009

[7] J.F. Douglas, J.M. Gasiorek, J.A. Swaffield, Fluid Mechanics, Pitman Publishing Limited, London, 1979 (ISBN 027300462X)

[8] F. Durst, B. Ünsal, S. Ray, D. Trimis, Method for defined mass flow variations in time and its application to test a mass flow rate meter for pulsating flows, Meas. Sci. Technol. 18 (2007) 790-802, http://dx.doi.org/10.1088/0957-0233/ $18 / 3 / 031$.

[9] S.G. Etemad, J. Thibault, S.H. Hashemabadi, Calculation of the Pitot tube correction factor for Newtonian and non-Newtonian fluids, ISA Trans. 42 (2003) 505-512, http://dx.doi.org/10.1016/S0019-0578(07)60001-9.

[10] N. Fonseca González, J. Casanova Kindelán, M. Valdés, Influence of the stop/ start system on $\mathrm{CO}_{2}$ emissions of a diesel vehicle in urban traffic, Transp. Res. Part D: Transp. Environ. 16 (2011) 194-200, http://dx.doi.org/10.1016/j. trd.2010.10.001.

[11] J.E. Gallagher, R.E. Beaty, P.J. Lanasa, Flow conditioner for more accurate measurement of fluid flow, U.S. Patent 5,495,872, 1996.

[12] J.G. Hawley, C.D. Bannister, C.J. Brace, A. Cox, D. Ketcher, R. Stark, Vehicle modal emissions measurement-techniques and issues, Proc. Inst. Mech. Eng. Part D: J. Automob. Eng. 218 (2004) 859-873, http://dx.doi.org/10.1243/ 0954407041581057.

[13] G.H. Henderson, M.J. Marthaler, J.J. Braun, V. Thomas, G. Pan, T.L. McKinley, Exhaust gas recirculation measurement device. U.S. Patent $6,810,725$ B2, 2003 .

[14] J. Heywood, Internal Combustion Engine Fundamentals, McGraw-Hill Education, United States, 1988 (ISBN 9780070286375).

[15] R. Klopfenstein Jr., Air velocity and flow measurement using a Pitot tube, ISA Trans. 37 (1998) 257-263, http://dx.doi.org/10.1016/50019-0578(98)00036-6.

[16] M. Kupnik, M. Gröschl, Ultrasonic-based gas flow meter for harsh environmental conditions, Elektrotechnik \& Informationstechnik 126 (2009) 206-213. http://dx.doi.org/10.1007/s00502-009-0638-0.

[17] M. Kupnik, A. Schroder, P. O'Leary, E. Benes, M. Groschl, Adaptive pulse repetition frequency technique for an ultrasonic transit-time gas flow meter for hot pulsating gases, IEEE Sens. J. 6 (2006) 906-915, http://dx.doi.org/10.1109/ JSEN.2006.876042.

[18] M. Kupnik, A. Schroder, P. O'Leary, E. Benes, M. Groschl, An ultrasonic transittime gas flow meter for automotive applications, in: Proceedings of IEEE Sensors 2004, IEEE, 2004, pp. 451-454. Doi: http://dx.doi.org/10.1109/ICSENS 2004.1426197.

[19] M. Kupnik, A. Schröder, M. Wiesinger, K.C. Harms, Ultrasonic gas flow meter as well as device to measure exhaust flows of internal combustion engines and method to determine flow of gases. U.S. Patent 7,093,502 B2, 2006

[20] F. Laurantzon, Flow Measuring Techniques in Steady and Pulsating Compressible Flows TeknL thesis, Royal Institute of Technology, Stockholm, Sweden, 2010.

[21] F. Laurantzon, R. Örlü, a Segalini, P.H. Alfredsson, Time-resolved measurements with a vortex flow meter in a pulsating turbulent flow using wavelet analysis, Meas. Sci. Technol. 21 (2010) 123001, http://dx.doi.org/10.1088/ 0957-0233/21/12/123001.

[22] F. Laurantzon, R. Örlü, N. Tillmark, H. Alfredsson, Response of common flow meters to unsteady flow. Technical Report KTH 2012

[23] G.W. Lewis, Calibration method for exhaust mass flow measuring system. U.S. Patent 4,823,591 A, 1989.

[24] G.H. Millar, Laminar flow element and flow meter. U.S. Patent 3,349,619 A, 1967.

[25] J.W. Miller, Evaluation of Portable Emissions Measurement Systems (PEMS) for inventory purposes and the not-to-exceed heavy-duty diesel engine regulation, Technical Final Report Contract No. 03-345, California Air Resources Board, 2006.

[26] S.-M. Liang, S.-J. Tsai, S.-F. Wang, An effective approach for calculation of exhaust pipe flows, J. Mech. 25 (2009) 177-188, http://dx.doi.org/10.1017/ \$172771910000263X

[27] R.C. Mottram, Introduction An overview of pulsating flow measurement, Flow Meas. Instrum. 3 (1992) 114-117.

[28] H. Nakamura, M. Adachi, I. Asano, J. Senda, S. Aoki, Method and apparatus for measuring exhaust gas flow rate and it's application system for analyzing the exhaust gases from an engine. U.S. Patent 7,110,878 B2, 2006.

[29] H. Nakamura, I. Asano, M. Adachi, J. Senda, Analysis of pulsating flow measurement of engine exhaust by a Pitot tube flow meter, Int. J. Engine Res. 6 (2005) 85-93, http://dx.doi.org/10.1243/146808705X7329.

[30] H. Nakamura, M. Akard, S. Porter, N. Kihara, M. Adachi, I.A. Khalek, Performance test results of a new on board emission measurement system conformed with CFR part 1065, SAE Int. J. Engines (2007), http://dx.doi.org/ 10.4271/2007-01-1326

[31] H. Nakamura, Vehicle-installed exhaust gas analyzing apparatus. U.S. Patent US 6,865,472 B2, 2005

[32] L. Rubino, P. Bonnel, R. Hummel, A. Krasenbrink, U. Manfredi, G. De Santi, et al., PEMS light duty vehicles application: experiences in downtown milan, SAE paper 2007-24-0113. Doi: http://dx.doi.org/10.4271/2007-24-0113.

[33] L. Rubino, P. Bonnel, A. Krasenbrink, M. Carriero, J. Kubelt, I. Fumagalli, et al., 
Development of an official test method for on-board PM measurements from Heavy-Duty diesel engines in the European Union, SAE Int. J. Engines (2007) 1567-1577, http://dx.doi.org/10.4271/2007-01-1946.

[34] S. Sato, T. Yamamoto, Y. Ogawa, Y. lizuka, Research on measurement method of exhaust gas flow rate for on-board measurement system, SAE International Journal of Engines, SAE paper 2007-01-4080. Doi: http://dx.doi.org/10.4271/ 2007-01-4080.

[35] B.C. Shade, A Performance Evaluation of the MEMS - An On-Road Emissions Measurement Study (Thesis), West Virginia University, United States, 2000

[36] W. Silvis, J. Williamson, N. Kreft, A. Alajbegovic, DVE - direct vehicle exhaust flow measurement using head-type flow meters, SAE International Journal of Engines paper 2003-01-0782. Doi: http://dx.doi.org/10.4271/2003-01-0782.

[37] V. Skwarek, H. Windorfer, V. Hans, Measuring pulsating flow with ultrasound, Meas.: J. Int. Meas. Confed. 29 (2001) 225-236, http://dx.doi.org/10.1016/ S0263-2241(00)00041-5.

[38] P. Soltic, $\mathrm{M}$. Weilenmann, $\mathrm{NO}_{2} / \mathrm{NO}$ emissions of gasoline passenger cars and light-duty trucks with Euro-2 emission standard, Atmos. Environ. 37 (2003) 5207-5216, http://dx.doi.org/10.1016/j.atmosenv.2003.05.003.
[39] P. Stainback, K. Nagabushana, Review of hot-wire anemometry techniques and the range of their applicability for various flows, Electron J. Fluids Eng. Trans. ASME (1997) (ISBN 0791809757).

[40] G. Tolentino, J. Abugaber, R. Tolentino, Calibración de tubos Pitot tipo s en el labinthap, Memorias Del Simp Metrol (2001).

[41] P.R. Tripathi, G. Eden, D.M. Soenen, C.D. Ensfield, H.M. Ryan, R.K. Zummer, Vehicle mass emission measurement. U.S. Patent 6,085,582 A, 2000.

[42] Vojtisek-Lom M. Portable on-board mass emissions measuring system. U.S. Patent 6,308,130 B1, 2001.

[43] M. Weilenmann, C. Bach, C. Rudy, Aspects of instantaneous emission measurement, Int. J. Veh. Des. 27 (2001) 94, http://dx.doi.org/10.1504/ IJVD.2001.001955.

[44] M.J. Zucrow, J.D. Hoffman, Gas Dynamics, Volume I. ISBN: 0-471-98440-X. 1976.

[45] 40 CFR 1065, Part J Engine Testing Procedures. Field Testing and Portable Emission Measurement Systems. US Fed Regist vol. 70, No. 133, 2005, pp. $40420-40612$. 